[15] Oleksienko, N., Obolkina, V., Dudko, S., Baldyniuk, O. (2015). Bezpechnist kondyterskoi produktsiyi: deiaki aspekty yii formuvannia. Prodovolcha industriia APK, 3, 37-40.

[16] Corrigendum to Regulation (EC) No 854/2004 of the European Parliament and of the Council of 29 April 2004 laying down specific rules for the organisation of official controls on products of animal origin intended for human consumption (2004). Official Journal of the European Union L 139, 83-127.

\title{
FEATURES OF DETERMINING THE QUALITY OF ETHNIC SOURDOUGHS AND WAYS OF USING THEM IN BAKING AND CATERING BUSINESS
}

\author{
Tetiana Lebedenko \\ Department of bread, confectionery, macaroni products and food concentrates technology \\ Odessa National Academy of Food Technologies \\ 112 Kanatna str., Odessa, Ukraine, 65039 \\ tatyanalebedenko27@gmail.com \\ Viktoriia Kozhevnikova \\ Department of hotel and catering business \\ Odessa National Academy of Food Technologies \\ 112 Kanatna str., Odessa, Ukraine, 65039 \\ kozhevnikova-viktoriya@ukr.net \\ Tamara Novichkova \\ Department of hotel and catering business \\ Odessa National Academy of Food Technologies \\ 112 Kanatna str., Odessa, Ukraine, 65039 \\ vicnov@ukr.net \\ Olena Kotuzaki \\ Department of bread, confectionery, macaroni products and food concentrates technology \\ Odessa National Academy of Food Technologies \\ 112 Kanatna str., Odessa, Ukraine, 65039 \\ elenalkotuzaki@gmail.com
}

\footnotetext{
Abstract

The usage of various sourdoughs increases in order to expand the range and improve the quality, nutritional properties, and safety of bread products. Spontaneous sourdoughs with different formulas and preparation parameters are used in technologies of popular ethnic products. This paper is devoted to the study of wheat spontaneous sourdoughs, such as hop, pea-anise, and wine yeast sourdough. The effect of the grade and baking properties of flour, the inclusion of additional ingredients that can act as enrichers of the nutrient medium, carriers of additional fermentation microorganisms, as well as controllers of the species composition of the microflora, on their quality has been studied.

The basic scheme of preparing spontaneous wheat sourdough is developed; the basic stages and parameters of the dilution and production cycles are noted. The methods of controlling the process and quality of sourdough are described, the recommended values of the lifting force and titrated acidity are presented, as well as sensory characteristics.
} 
It has been established, that the required fermentation ability and acid accumulation rate of sourdough are obtained in different time: 24 hours for wine yeast sourdough, 7-8 days for hop sourdough, and up to 15 days of a dilution cycle for pea-anise sourdough. The stabilizing effect of active substances of hop and anise on the quality of sourdough has been proven. Hop and pea-anise sourdough retain the necessary biotechnological properties for 90 days of propagation, but wine yeast sourdough loses its quality after 30 days, sourdough without additives loses it after 9 days.

The results of the research have theoretical and practical use, since the proposed scheme and approaches to developing the wheat sourdough technology and controlling their quality can be used to study various ethnic sourdoughs and technology of bread based on them. The experimental data on the quality of selected sourdoughs can be used to develop the technology of bread products with improved quality, nutritional value, and safety, ethnic products, and products "made according to old technologies".

Keywords: spontaneous wheat sourdough, hop sourdough, pea-anise sourdough, wine yeast sourdough, biotechnological properties.

DOI: $10.21303 / 2504-5695.2019 .00971$

\section{Introduction}

Analyzing the situation at the bread market and assessing the current realities of bread product manufacture showed the increased demand of consumers and nutritionists towards the sensory properties, naturalness, and safety of products, as well as their range. Consumers prefer products without synthetic and genetically modified ingredients that are made, using easily understood technologies. Health care draws attention to the issues of preserving and enhancing valuable physiological properties of bread products, reducing possible risks of negative effects due to the use of more valuable traditional raw materials and the inclusion of innovative ingredients which are modified during technological processing. The desire to get pleasure from food increases the demands of consumers to the flavor of products, the brightness of the taste and aroma of traditional products and specific features of ethnic and improved products. The products of different peoples and tastes are gaining popularity, including ethnic, "craft", etc. [1, 2]. Affordability, long shelf life, and high resistance to microbiological damage are also important for bakery products. Mini-bakeries, producing pastries in catering establishments and supermarkets, have a more favorable position in the bread market due to the faster adaptation of product range to consumer demands, lower sale costs due to the possibility of production and trade in one place, and flexible pricing policy [3]. Customers of catering industry, on one hand, are ready to pay more but, on the other hand, are much more demanding towards the quality of products, compliance to their expectations, range variety, etc.

The quality problems of the main raw material (wheat flour), such as content reduction, excessive gluten elasticity, reduced enzyme activity, increased microbiological contamination, etc., complicate the production of quality bread products [4]. The use of new raw materials with valuable physiological properties (whole wheat flour, bran, flour of other cereals, legumes, and other crops) also causes problems in the formation of the proper quality, resistance to the microbiological damage, and digestibility of products [5-7].

Sourdoughs are becoming increasingly wider used in order to solve the aforementioned problems. By production type and microflora origin, they can be divided into:

1) commercial, made from pure cultures, obtained, using hybridization or mutagenesis;

2) commercial, made from pure cultures, isolated from natural sources;

3) spontaneous fermentation sourdoughs;

4) industrial sourdoughs. By moisture content and, accordingly, the recommendations for storage and use, they are divided into liquid, thick, and dry sourdoughs $[8,9]$.

The first group of sourdoughs, despite the higher predictability and stability in the technological process, somewhat lost its popularity due to the lack of consumer confidence in genetically modified organisms. The dough preparation with spontaneous sourdough is the oldest method, and today consumers, nutritionists, and producers of bread products are interested in its revival. This method of bread preparation is complex and long, which ensures the accumulation of precursors of taste and aroma, improving the digestibility of proteins, vitamins and minerals, lowering the glycemic index of 
carbohydrates, and obtaining products more resistant to staling and microbiological damage [8, 10]. The quality of sourdough and the duration of the dilution cycle depend on the chemical composition, biochemical, and microbiological characteristics of the raw materials, especially flour, but it is also to a large extent affected by additional ingredients. Thus, the type, variety, and baking properties of flour, as well as the inclusion of enrichers, determine the degree of compliance of the nutrient medium with the needs of the fermentative microflora in terms of balance and availability of nutrients and biostimulants. The flour itself is a carrier of both fermentative and extraneous microflora, which can change the course of the technological process and cause damage to finished products. The initial species composition of the microflora in the water-flour system may change with the addition of microflora carriers. The presence of compounds with selective antiseptic properties, which can be introduced with non-traditional raw materials and formed during sourdough ripening, also affects the efficiency of the dilution cycle, primarily the development and activity of yeast and lactic acid bacteria that cause the formation of high quality bread and inhibition of foreign microorganisms which can change the normal course of fermentation and reduce the quality of products [11].

That is why significant fluctuations in the biotechnological properties of sourdough, the species composition of the microflora and, consequently, their ability to ensure the formation of bread products of proper quality, depending on the formulas, region [12], fermentation parameters, production conditions [13], etc. are established.

Therefore, it is necessary to study the quality of sourdoughs, prospective for use in Ukrainian bread-baking: hop, pea-anise, and wine yeast sourdough. The development of recommendations for monitoring the quality of sourdoughs at all stages of their preparation is also relevant.

The purpose of this study was to determine the quality of selected sourdoughs, their prospects for solving the problems of the industry, which would improve the consumer properties, nutritional value, and stability of bread products during storage.

In order to achieve this goal, the following tasks were formulated:

- to develop a basic scheme of quality control for spontaneous wheat sourdough, select the most important properties, and effective methods of their determination;

- to determine the quality of hop, pea-anise, and wine yeast sourdough, as well as technological features of their preparation and use;

- to establish prospective ways of using these sourdoughs to solve the problems of bread making.

\section{Materials and methods}

\section{1. Studied objects and materials}

Two samples of TM "Bohumila" (Ukraine) wheat flour were used for sourdough and bread production: sample 1 was 1st grade flour; sample 2 was high grade flour. Flour quality characteristics correspond to those, listed in GSTU 46.004-99; they are presented in Table 1.

Table 1

Baking properties of wheat flour $(n=3, p \leq 0,95)$

\begin{tabular}{lcc}
\hline \multicolumn{1}{c}{ Properties } & Sample 1 & Sample 2 \\
\hline Moisture content, \% & 10.3 & 12.5 \\
Gluten quality (group): & II & II \\
- raw gluten content, \% & 26.0 & 27.8 \\
- extensibility & Average & Average \\
- elasticity, IDK-1 units & 55 & 66 \\
- hydration ability, $\%$ & 168.1 & 178.0 \\
Falling number, s & 252 & 296 \\
Gas production ability, $\mathrm{cm}^{3} \mathrm{CO}_{2}$ & 1400 & 1600
\end{tabular}


Other basic and additional raw materials that met the requirements of the relevant regulations were used: food-grade salt(DSTU 3583-97); table sugar(DSTU 4623:2006); sunflower oil(DSTU 4492:2005); non-fermented malt from Zhytomyr distillery (DSTU 4282:2004); peas (DSTU 4523:2006); type 90 fine "UA-AROMA" aromatic grade granulated hop (DSTU 4099-02) from the scientific-industrial enterprise "WESTHOPS" (city of Brody, Ukraine); anise (GOST 18315-78).

Samples of spontaneous wheat sourdough were prepared in three variations, according to the scheme, depicted in Fig. 1:

1) pea and anise sourdough, made from pea-anise extract according to [14];

2) hop sourdough, the parameters of which were established in [10];

3) sourdough, made, using dried wine yeast in the dilution cycle, as described in [15].

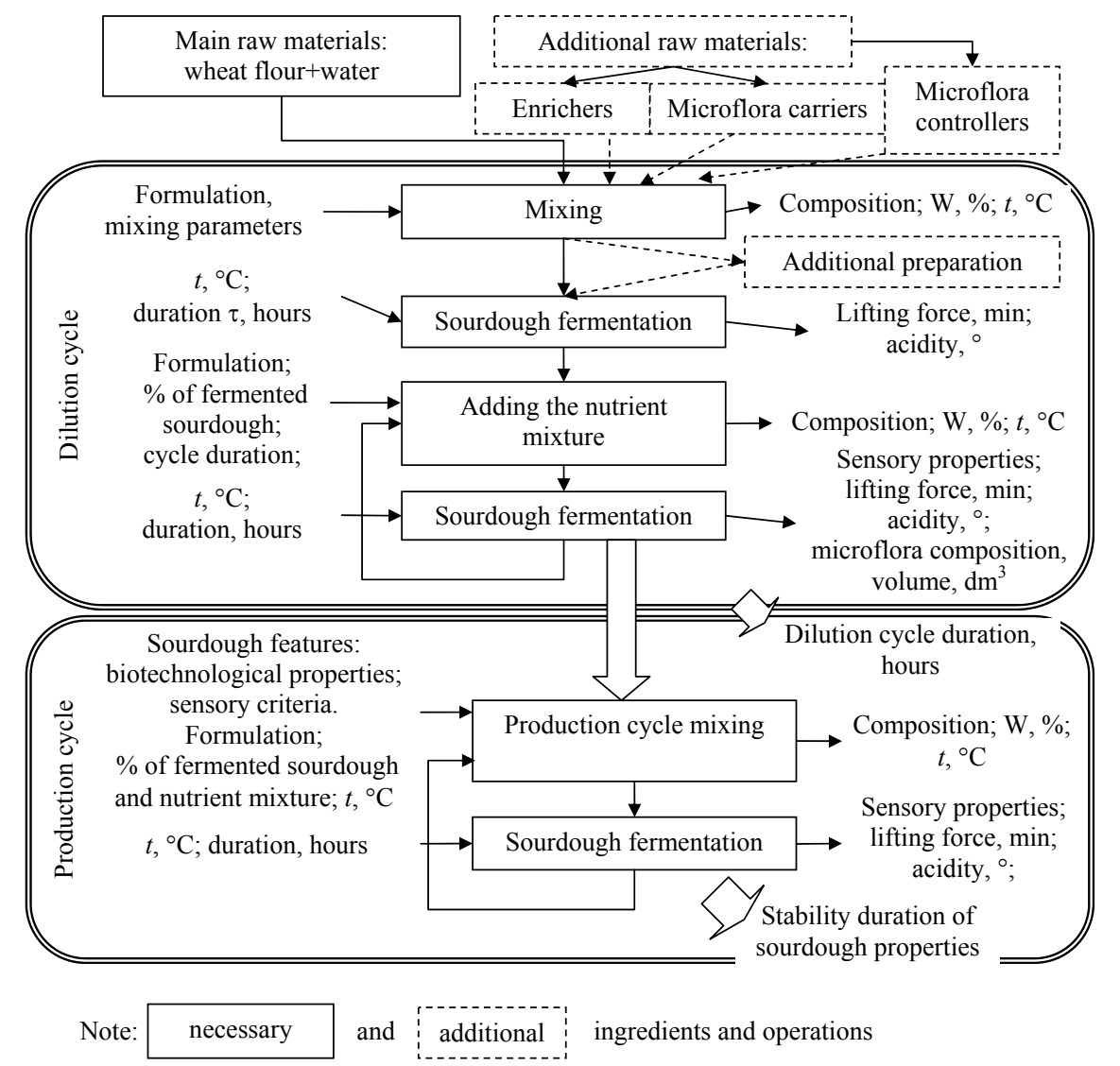

Fig. 1. Basic scheme of spontaneous wheat sourdough preparation

Common to them is the presence of dilution and production cycles; high grade and 1st grade wheat flour are used as the main source of nutrients, enzymes, and fermentation microflora. In the dilution cycle, the nutritional mixture was prepared and conditions for colloidal and enzymatic processes and the development of the spontaneous fermentative microflora and the accumulation of products of its metabolism were created. During the dilution phase a nutritional mixture was used for replenishment for several cycles until the required volume of sourdough was reached with the required lifting force, acidity, microflora composition, and sensory characteristics.

A special feature of hop sourdough preparation is the additional use of hop extract and sugar solution to enrich the nutritional mixture with a number of biostimulants and control the development of the sourdough microflora due to antiseptic compounds of hop.

When preparing pea-anise sourdough with additional ingredients (peas and anise), new microflora is introduced, the nutrient medium is enriched with rare components, and the latter also acts as a species composition controller for the sourdough microflora. 
Preparing sourdough with dried wine yeast, which is a carrier of nutrients and fermentative microflora, includes an additional stage of preparing the nutrient medium. Gelatinizing and saccharifying the water-flour mixture with white malt enzymes allows to make its composition closer to wine wort, which is turned into wine due to primarily yeast.

In the production cycle, part of ripe sourdough (50-75\%) was removed and used to prepare the dough. A nutrient mixture was added to the rest; its main ingredients were wheat flour and water, after which the mixture was left for ripening, acquiring the necessary biotechnological properties.

In order to determine the moisture content of flour and sourdoughs, a drying cabinet SESh3M was used (Fig. 2, a). A manual titration installation was used to study their acidity (Fig. 2, b). The gas production ability of the flour was determined using a fermentation control device AG-1M. The activity of hydrolytic enzymes was evaluated by the falling number using the PChP-3 device (Fig. 2,c). To create the specified temperature and humidity conditions during sourdough ripening and determine their lifting force and species composition of the microflora by its cultivation on different nutrient media, the dry-air thermostat TC-80 was used (Fig. 2, $d$ ).

Appearance, size, shape, content of granulose, amount of the fermentative and extraneous microflora in flour and sourdough were determined, using a biological microscope XS-5510 MICromed (Fig. 2,e).

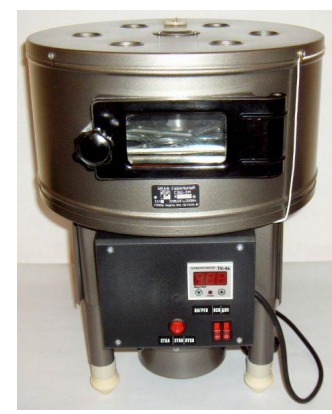

$a$

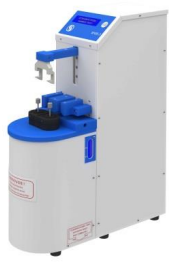

c

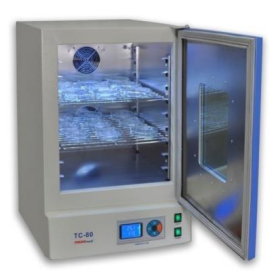

$d$

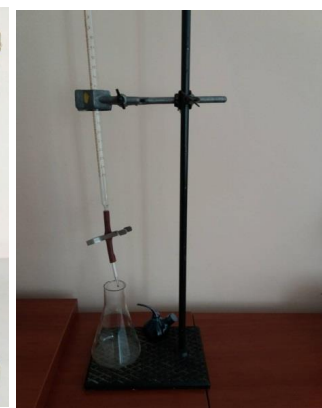

$b$

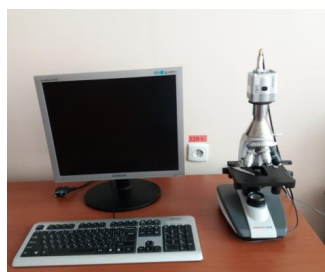

e

Fig. 2. Instruments and equipment used to determine the quality of flour and sourdough: $a$ - drying cabinet SESH-3M; $b$ - manual titration installation; $c$ - PCHP-3 device; $d$-dry-air thermostat TC-80; $e$ - biological microscope XS-5510 MICROmed

\section{2. Methods of determining the sensory, physical, chemical, and biotechnological properties of raw materials and sourdoughs}

The moisture content was determined by drying to a constant mass in a drying cabinet at $105{ }^{\circ} \mathrm{C}$, the lifting force - by the rising speed of the dough ball, made from $30 \%$ of sourdough and flour, and the total acidity - by titration of the half-finished product by $0.1 \mathrm{~N} \mathrm{NaOH}$ solution [16].

The microbiological analysis of the sourdoughs was carried out by evaluating the morphological properties of the yeast and lactic acid bacteria by microscopy of the uncolored "crushed drop" preparation and directly counting the cells of fermentative microorganisms in a Goryaev chamber (hemocytometer), using the Burgvits method. The activity of lactic acid bacteria was calculated, based on the intensity of blue color recovery of methylene blue. To detect and count the foreign microflora in flour and sourdough, the Koch method was used to seed a thick selective 
nutrient medium. A synthetic medium with lysine was used for wild yeast, milk agar for rotting bacteria, meat peptone agar for spore bacteria (potato and hay bacillus), agarized cabbage medium for lactic acid bacteria, and wort agar for yeast molds [17, 18].

\section{Results}

In this study, sourdough was made, using hop extract (sample 1), pea-anise extract (2), and wine yeast (3). First grade (a) and high grade (b) wheat flour was used as a base. Their baking properties did not differ significantly (Table 1), but their microbiological composition was different (Table 2).

High grade flour met the requirements of regulatory documents, but the first grade flour had too high mold fungi content and general microbial contamination. This can negatively affect the formation of sourdough properties in the dilution cycle, their stability in the production and, consequently, the quality of products.

Table 2

Microbiological parameters of wheat flour

\begin{tabular}{|c|c|c|c|c|c|c|}
\hline \multirow{3}{*}{ Flour samples } & \multicolumn{6}{|c|}{ Main and extraneous microorganism content, $\mathrm{CFU} / \mathrm{g}$} \\
\hline & \multicolumn{2}{|r|}{ yeast } & \multirow{2}{*}{$\begin{array}{l}\text { lactic acid } \\
\text { bacteria }\end{array}$} & \multirow{2}{*}{$\begin{array}{l}\text { hay bacillus } \\
\text { spores }\end{array}$} & \multirow{2}{*}{ mold fungi } & \multirow{2}{*}{ MAFAM } \\
\hline & cultivated & wild & & & & \\
\hline $1^{\text {st }}$ grade (a) & \multirow{2}{*}{ not found } & 132 & $3.1 \times 10^{2}$ & $1.8 \times 10^{2}$ & $2.2 \times 10^{2}$ & $4.7 \times 10^{3}$ \\
\hline High grade (b) & & 78 & $1.9 \times 10^{2}$ & $1.2 \times 10^{2}$ & $1.8 \times 10^{2}$ & $1.3 \times 10^{3}$ \\
\hline SNiP regulations [19] & - & no more than 100 & - & no more than 200 & $\begin{array}{l}\text { no more } \\
\text { than } 200\end{array}$ & no more than $5 \times 10^{3}$ \\
\hline
\end{tabular}

In the dilution cycle, the moisture content of the sourdough was determined after the first mixing and each replenishment with a nutrient mixture with the moisture content of $69-72 \%$. It ripened at $29-32{ }^{\circ} \mathrm{C}$, the replenishment was made every 24 hours.

In order to monitor the process of their ripening, sensory parameters were evaluated, as well as the lifting force (Fig. 3, 4), which shows the intensity of yeast activity, and titrated acidity, which reflects the activity of lactic acid bacteria (Fig. 5). Signs of the sourdough readiness for dough preparation that are the end of the dilution cycle are the volume increase, typical for fermentation products flavor, increased acidity and lifting force values of 20-25 minutes.

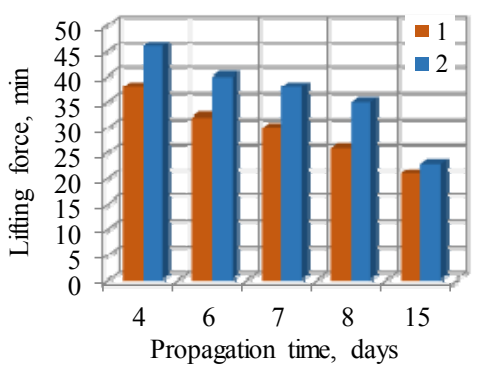

$a$

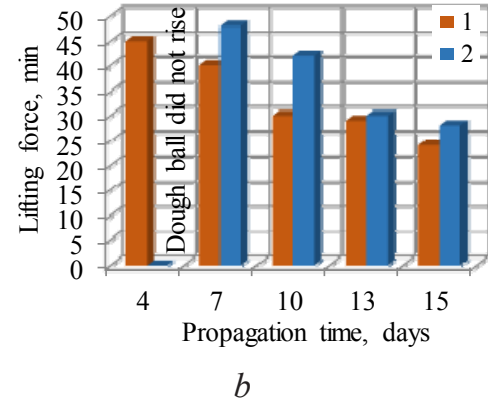

Fig. 3. Changes in lifting force during wheat sourdough propagation:

$a$ - hop sourdough; $b$ - pea-anise sourdough; 1 - first grade flour; 2 - high grade flour

As can be seen from the graphical interpretation of the obtained data, samples of spontaneous wheat sourdough acquire the requisite fermentation capacity after a different number of replenishment cycles. The earliest to acquire the requisite activity after 24 hours, that is, one cycle, is the sourdough with wine yeast, provided that the nutrient mixture is gelatinized saccharified 1st 
grade flour, with high grade flour being a little slower (Fig. 4). Sourdough with water-flour mixture requires 3-4 days (1st grade flour) to 15 days (high grade flour).

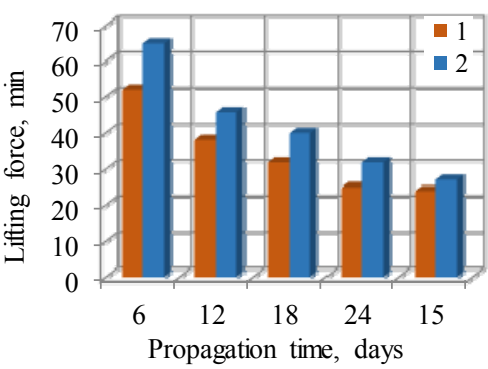

$a$

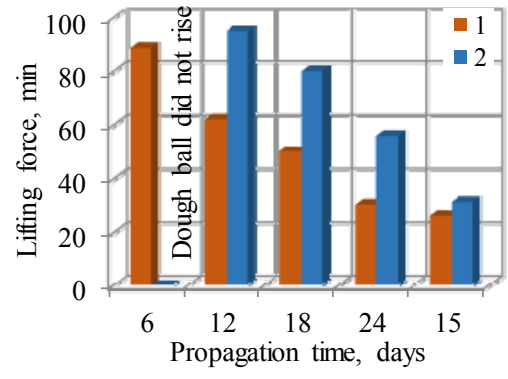

$b$

Fig. 4. Changes in lifting force during wheat sourdough propagation with wine yeast: $a$ - with gelatinized saccharified flour; $b$ - with water-flour mixture;

1 - first grade flour; 2 - high grade flour

Sourdough with a hop extract (Fig. 3) and 1st grade flour requires 7-8 cycles, i. e. 7-8 days, or up to 10 days if using high grade flour. Pea-anise sourdough (Fig. 3) requires at least 15 replenishment cycles for ripening; it is also advisable to use 1st grade flour. This is due to the creation of more favorable conditions by the content of nutrients and biostimulants, as well as the spontaneous fermentation microflora.

Changes in acidity (Fig. 5) in samples of 1st grade flour, which has the increased microbiological contamination (Table 2), indicate the rapid activation of acid-forming bacteria.

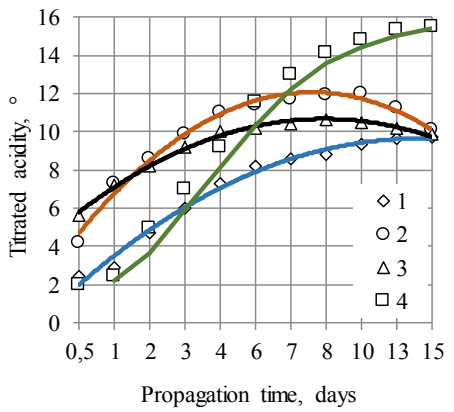

$a$

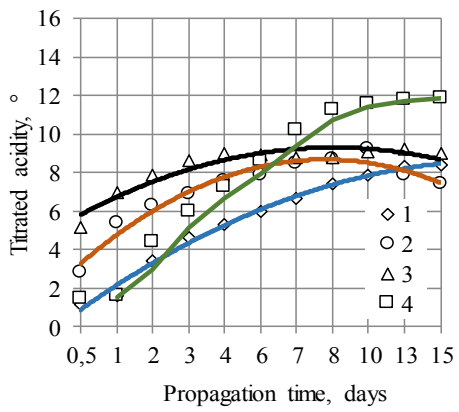

$b$

Fig. 5. Acidity accumulation during sourdough propagation with different grades of wheat flour: $a$ - first grade flour; $b$ - high grade flour; 1 - sourdough with hop extract; 2 - sourdough with pea-anise extract; 3 - sourdough with wine yeast; 4 - sourdough with water

The analyzed property increases during the first 3-4 days of propagation, especially in samples with pea-anise extract and wine yeast, which could be due to their greater presence and more favorable environmental conditions. Slower acid accumulation in this period takes place in samples with hop extract and control, where the sourdough was made only from flour and water in order to determine the effect of additional ingredients on this process. But in the control sample there is the acidity growth intensification between 4 th and 13th day of propagation, and at the end the acidity is $15.3^{\circ}$. In the studied samples, the process slows down from the 6 th day and the acidity is set in the range of $9.7-10.5^{\circ}$.

Sourdough samples had general and specific features of sensory properties (Fig. 6).

General signs of fermentation (volume increase and aroma of alcohol and lactic acid fermentation products) were typical for all samples. The differences consisted of hop sourdough, having a more vivid, pleasant lactic acid aroma with a slight hop tinge and a light gray color. Pea-anise sourdough had a fruitier aroma and a lighter color. Specific for sourdough with wine 
yeast is the predominance of aroma of alcoholic fermentation products and grapes as well as a darker color (Fig. 6).

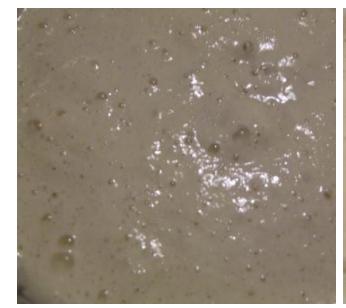

$a$

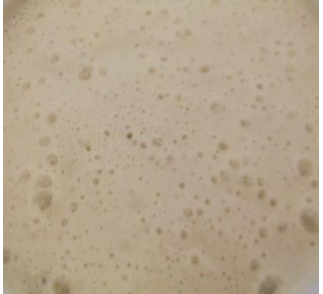

$b$

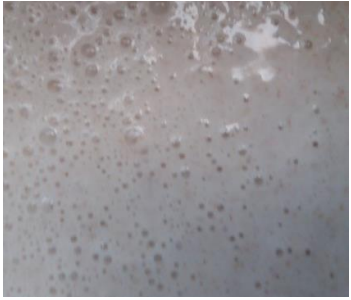

c

Fig. 6. Photos of sourdoughs after the dilution cycle: $a$ - hop sourdough; $b$ - pea-anise sourdough; $c$ - wine yeast sourdough

In order to determine the stability duration of sourdough with the moisture content of $68-$ $72 \%$ in the production cycle, the basic technological properties (lifting force and titrated acidity) were measured for 90 days. Sourdough samples were propagated in conditions, identical to the industrial ones: temperature of $30 \pm 2{ }^{\circ} \mathrm{C}$, removal of $25 \%$ of ripe sourdough and its replenishment with $75 \%$ of the nutrient mixture every 24 hours (Table 3 ).

Table 3

Quality characteristics of spontaneous sourdough in production cycle

\begin{tabular}{|c|c|c|c|c|c|c|}
\hline \multirow{2}{*}{ Sourdough } & \multicolumn{6}{|c|}{ Propagation time, days } \\
\hline & 9 & 15 & 30 & 45 & 60 & 90 \\
\hline \multicolumn{7}{|c|}{ Lifting force of sourdough made from $1^{\text {st }}$ grade flour, min } \\
\hline Hop & 23 & 21 & 23 & 25 & 27 & 28 \\
\hline Pea-anise & 29 & 23 & 20 & 21 & 23 & 22 \\
\hline With wine yeast & 18 & 21 & 24 & 27 & 35 & 46 \\
\hline Without additives & 29 & 44 & 57 & 63 & 70 & $-*$ \\
\hline \multicolumn{7}{|c|}{ Lifting force of sourdough made from high grade flour, min } \\
\hline Hop & 32 & 23 & 23 & 24 & 25 & 27 \\
\hline Pea-anise & 41 & 28 & 27 & 26 & 25 & 24 \\
\hline With wine yeast & 28 & 25 & 29 & 38 & 42 & 65 \\
\hline Without additives & 35 & 51 & 66 & 95 & $-*$ & $-*$ \\
\hline \multicolumn{7}{|c|}{ Titrated acidity of sourdough made from $1^{\text {st }}$ grade flour, ${ }^{\circ}$} \\
\hline Hop & 9.5 & 9.7 & 9.8 & 10.0 & 10.1 & 10.3 \\
\hline Pea-anise & 11.7 & 11.8 & 11.4 & 11.4 & 11.3 & 11.2 \\
\hline With wine yeast & 10 & 10.4 & 10.2 & 12.6 & 14.0 & 16.5 \\
\hline Without additives & 14.2 & 15.5 & 17.3 & 18.6 & 19.8 & -* \\
\hline \multicolumn{7}{|c|}{ Titrated acidity of sourdough made from high grade flour, ${ }^{\circ}$} \\
\hline Hop & 7.8 & 7.8 & 8.0 & 8.1 & 8.3 & 8.4 \\
\hline Pea-anise & 8.3 & 8.9 & 8.5 & 7.9 & 7.7 & 7.6 \\
\hline With wine yeast & 8.8 & 9.0 & 9.4 & 11.3 & 12.9 & 14.8 \\
\hline Without additives & 10.5 & 11.9 & 13.1 & 14.6 & $-*$ & -* \\
\hline
\end{tabular}

Note: -* sourdough propagation was stopped; _ _ low quality; - loss of technological properties 
It was established, that spontaneous liquid sourdough with hop and pea-anise extracts are characterized by the relative stability of technological properties during their propagation for 90 days, which correlates with the previous results. For the sourdough with wine yeast, it is expedient to use 1st grade flour and the duration of their propagation in the production cycle should not exceed 30 days.

\section{Conclusions}

The results of the research confirm the prospects of using spontaneous wheat sourdough to manufacture bread products. The basic stages and parameters of sourdough preparation in dilution and production cycles are established. The basic scheme of the sourdough technology, noting the selected properties for the quality control (lifting force, titrated acidity, and sensory characteristics) has been developed. The recommended values and methods of their evaluation are given.

The effect of the grade and properties of flour, as well as the inclusion of the hop extract, pea-anise extract, and dried wine yeast on the quality of sourdough has been determined. The efficiency of using $1^{\text {st }}$ grade flour, despite the increased microbiological contamination, has been proven. It is shown, that wine yeast sourdough obtains the necessary properties in 24 hours, while hop sourdough requires 7-8 days and pea-anise sourdough requires up to 15 days of dilution cycle. This points out to some difficulties in introducing time-consuming technologies at the enterprises of baking and restaurant business.

It has been established, that hop and pea-anise sourdough retain the fermentation ability and required acid accumulation rate for up to 90 days, but the production cycle of wine yeast sourdough should not exceed 30 days. The relatively long stability of these sourdoughs allows us to assume the possibility of using hop and anise extracts to prolong the stability of other types of sourdough. It also allows to predict the possibility of sourdough propagation with the required fermentation, daily replenishment, and 90-day use in specialized enterprises that will sell them to bread producers.

The proposed approaches to the development and control of the wheat sourdough technology can be used to study other ethnic sourdoughs. Their implementation will allow the baking and catering business to expafnd its range and improve the product quality. But further research on the impact of different recipes and other raw materials on the technology and quality of sourdough are required. This will be the basis for formulating the requirements for the baking properties of raw materials and developing technological instructions for sourdough preparation and using them for bread product manufacture, which will allow to predict the course of the technological process and the quality of semi-finished and finished products.

\section{References}

[1] Krykavskyi, Ye. V., Stets, O. M. (2017). Pozytsionuvannia na tli trendiv svitovoho rynku kharchovykh produktiv. Suchasni trendy povedinky spozhyvachiv tovariv i posluh. Rivne: RDHU, 68-69.

[2] Eglite, A., Kunkulberga, D. (2017). Bread choice and consumption trends. Baltic Conference on Food Science and Technology FOODBALT "Food for consumer well-being". Latvia University of Life Sciences and Technologies, 11, 178-182. doi: http:// doi.org/10.22616/foodbalt.2017.005

[3] Korniichuk, A. A. (2018). Peculiarities of commercial activity of bakery enterprises. Problems of Theory and Methodology of Accounting, Control and Analysis, 2 (40), 28-32. doi: http://doi.org/10.26642/pbo-2018-2(40)-28-32

[4] Zhyhunov, D. O., Kovalova, V. P., Zhyronkina, D. S. (2017). Analiz yakosti boroshna z riznykh rehioniv Ukrainy. Naukovi pratsi ONAKhT, 81 (2), 35-43.

[5] Zhyhunov, D. O., Voloshenko, O. S., Khorenzhyi, N. V. (2018). Porivnialne doslidzhennia pokaznykiv yakosti tsilnozernovoho pshenychnoho ta speltovoho boroshna vitchyznianoho vyrobnytstva. Zernovi produkty i kombikormy, 18 (1.3), 15-20.

[6] Navneet, S. D. (2018). Whole Wheat Flour Stability: An Insight. Acta Scientific Nutritional Health, 2 (3), 8-18. Available at: https://www.actascientific.com/ASNH/ASNH-02-0055.php Last accessed: 15.07.2019

[7] Ertl, K., Goessler, W. (2018). Grains, whole flour, white flour, and some final goods: an elemental comparison. European Food Research and Technology, 244 (11), 2065-2075. doi: http://doi.org/10.1007/s00217-018-3117-1 